\title{
Efeito da secagem natural e artificial da biomassa foliar de Piper hispidinervum na composição química do óleo essencial
}

\section{Effect of the natural and artificial drying of leaf biomass Piper hispidinervum on the chemical composition of the essential oil}

\author{
Marília Pereira Machado ${ }^{1 *}$; Celso Luis Bergo ${ }^{2}$; Cícero Deschamps 3 ; \\ Humberto Ribeiro Bizzo ${ }^{4}$; Luiz Antonio Biasi ${ }^{5}$
}

\section{Resumo}

Piper hispidinervum C.DC. é uma planta nativa da Amazônia, produtora de óleo essencial rico em safrol. O objetivo do presente trabalho foi avaliar o efeito de diferentes métodos de secagem da biomassa folia de pimenta longa (P. hispidinervum), cultivada em Morretes (PR), na composição química do óleo essencial. Os tratamentos avaliados foram: folhas frescas; secagem natural por 6 e 12 dias; secagem em estufa à $40^{\circ} \mathrm{C}$ por 6 e 12 dias. $\mathrm{O}$ óleo essencial foi extraído por hidrodestilação a partir de amostras de $50 \mathrm{~g}$ de cada tratamento em triplicata. A determinação da composição química do óleo essencial foi realizada por cromatografia gasosa acoplada ao espectrômetro de massa (GC/MS). O delineamento experimental foi inteiramente casualizado, com três repetições e quatro plantas por parcela. Os dados obtidos foram submetidos à análise de variância. O tipo e tempo de secagem alteram a constituição química do óleo essencial de pimenta-longa. A secagem em estufa a $40^{\circ} \mathrm{C}$ durante 12 dias reduziu a quantidade de constituintes do óleo essencial, porém com aumento do teor de safrol.

Palavras-chave: Piperaceae, pimenta longa, hidrodestilação

\begin{abstract}
Piper hispidinervum C.DC. is a plant native to the Amazon region, produces an essential oil rich in safrole. The aim of this study was to evaluate the effect of different methods of drying biomass in chemical composition of the essential oil of P. hispidinervum cultivated in Morretes (PR). The treatments were: fresh leaves; natural drying for 6 and 12 days; oven drying at $40^{\circ} \mathrm{C}$ for 6 and 12 days. The essential oil was extracted by hydrodistillation from samples of $50 \mathrm{~g}$ of each treatment in triplicate. The chemical composition of essential oil was performed by gas chromatography coupled to mass spectrometer (GC/ MS). The experimental design was completely randomized design with three replication and four plants per plot. Data were subjected to analysis of variance. The type and drying time changes the chemical composition of the essential oil of $P$. hispidinervum. The dried at $40^{\circ} \mathrm{C}$ for 12 days reduce the amount of essential oil components, but with increasing content of safrole.
\end{abstract}

Key words: Piperaceae, long-pepper, hydrodistillation

\footnotetext{
Pesquisadora, Universidade Federal do Paraná, UFPR, Curitiba, PR.E-mail: ma_rilia10@hotmail.com

Pesquisador, Embrapa Acre, Rio Branco, AC. E-mail: celso@cpafac.embrapa.br

Prof. Dr. Associado da UFPR, Curitiba, PR. E-mail: cícero@ufpr.br

Pesquisador, Embrapa Agroindústria de Alimentos, Rio de Janeiro, RJ. E-mail: humberto.bizzo@embrapa.br

Prof. Dr. da UFPR, Curitiba, PR. E-mail: biasi.ufpr@gmail.com

* Autor para correspondência
} 
Piper hispidinervum C.DC., pertencente à família Piperaceae e popularmente conhecida como pimenta longa, é uma planta nativa da Amazônia que possui porte arbustivo, podendo alcançar até sete metros de altura (VAN DEN BERG, 1983). É considerada uma planta rústica, muito exigente em água e luz e aparece com frequência em áreas de capoeira (EMBRAPA, 2009). Apresenta grande potencial para produção de óleo essencial com teor médio de 2 a $5 \%$ em relação à matéria seca (RIVA et al., 2011), demonstrando ter efeito inibitório no crescimento in vitro dos fitopatógenos Bipolaris sorokiniana, Fusarium oxysporum, Colletotrichum gloeosporioides (ZACARONI et al., 2009) e Alternaria alternata (NASCIMENTO et al., 2008).

O óleo essencial extraído da pimenta longa apresenta um teor de $82 \%$ a $98,12 \%$ de safrol (MAIA et al., 1987; LIMA et al., 2009). O safrol (4-alil-1,2-metilenodioxibenzeno) é um éter fenólico do grupo dos anilpropanóides, com fórmula molecular $\mathrm{C}_{10} \mathrm{H}_{10} \mathrm{O}_{2}$, peso molecular de 162,18 $\mathrm{g}$ e densidade a $20^{\circ} \mathrm{C}$ de 1,096 (ROCHA; MING, 1999), com ponto de ebulição de $323^{\circ} \mathrm{C}-235^{\circ} \mathrm{C}$, e que solidifica a uma temperatura de $11^{\circ} \mathrm{C}$. É um líquido levemente amarelo de odor característico, insolúvel em água e solúvel em solventes orgânicos, tais como álcool, clorofórmio e éter etílico. Embora apresente comprovada atividade carcinogênica in vitro, é de grande importância científicotecnológica como precursor de uma variedade de compostos, especialmente, fármacos, bioinseticidas biodegradáveis, fixadores de aroma e, mais recentemente, de drogas antitrombóticas e auxinas endólicas (ROSA et al., 2000; PIMENTEL, 2000). É usado pelas indústrias químicas para fabricação de heliotropina (fixador de aroma) e butóxido de piperonila, que é utilizado em inseticidas e pesticidas naturais (PIMENTEL, 2000). A ação inseticida do safrol foi comprovada em teste de laboratório para a lagarta Spodoptera frugiperda (LIMA et al., 2009).

A maior concentração do óleo essencial da pimenta longa está presente nas folhas, em torno de $98 \%$, seguida dos ramos jovens. Folhas e ramos jovens apresentam de 50 a $60 \%$ de umidade, que deve ser reduzida logo após a colheita para evitar fermentação da biomassa antes da destilação, cujo efeito é prejudicial ao teor e à qualidade do óleo essencial (FIGUEIREDO et al., 2004). O excesso de umidade em matérias-primas vegetais também permite a ação de enzimas, podendo acarretar a degradação de constituintes químicos, além de possibilitar o desenvolvimento de fungos e bactérias (FARIAS, 2007). Segundo Simões e Spitzer (2007), em Piperaceae o óleo essencial ocorre em células parenquimáticas diferenciadas. Assim, no processo de secagem das folhas, além da redução do excesso de umidade, supõe-se que as estruturas das células vegetais são danificadas, facilitando a extração do óleo essencial.

O processo de secagem da pimenta longa é a etapa mais importante pós-colheita, pois a extração de óleo essencial da biomassa fresca não permite a obtenção do teor mínimo de safrol (90\%) exigido pelos mercados consumidores para a comercialização. Durante a secagem, a fração química mais volátil do óleo essencial é eliminada pelo arraste do vapor d'água, elevando a concentração do safrol (PIMENTEL; MIRANDA, 2001).

A secagem de um produto pode ser realizada empregando-se ar ambiente ou ar movimentado artificialmente, sendo estes métodos classificados como secagem natural e secagem artificial, respectivamente.

Considerando a demanda mundial por óleos ricos em safrol, o presente trabalho teve por objetivo avaliar diferentes métodos de secagem da biomassa no teor de safrol do óleo essencial de pimenta longa (P. hispidinervum).

Foram coletadas sementes de 40 plantas de pimenta longa (Piper hispidinervum) provenientes do banco de germoplasma da Embrapa Acre (958'22” S, 6748'40” W). A espécie foi identificada e depositada no Herbário do Museu Botânico Municipal de Curitiba, sob número de registro 347747. 
Para a coleta e preparo das sementes foram realizados os procedimentos segundo Cavalcante (2002), em que as espiguetas maduras foram coletadas manualmente e imersas por 24 horas em água e em seguida amassadas em peneira de polietileno de 230 mesh para liberação das sementes e retirada da mucilagem. Após, as sementes foram secas sobre papel ao ar livre, em local sombreado e ventilado durante $72 \mathrm{~h}$, e armazenadas em recipientes da cor âmbar, hermeticamente fechados, a $10^{\circ} \mathrm{C}$ até o momento da semeadura.

As mudas foram produzidas em condições de casa de vegetação, sendo a semeadura realizada a lanço em bandejas plásticas de $40 \times 30 \times 10 \mathrm{~cm}$, contendo substrato comercial, em abril de 2007. As bandejas permaneceram sob irrigação intermitente, com três períodos de rega: $15 \mathrm{~s}$ a cada $15 \mathrm{~min}$, das 08:00 $\mathrm{h}$ às 17:00; $15 \mathrm{~s}$ a cada hora, das 17:00 $\mathrm{h}$ às 23:00 h; e $15 \mathrm{~s}$ a cada $3 \mathrm{~h}$, das 23:00 h às 08:00 h.

Após 70 dias da semeadura, as plântulas, com aproximadamente $3,0 \mathrm{~cm}$ de altura, foram transplantadas para tubetes de $280 \mathrm{~cm}^{3}$ de volume. As mudas permaneceram em casa de vegetação com irrigação diária manual, durante o período de quatro meses.

As mudas com aproximadamente $20 \mathrm{~cm}$ de altura foram estabelecidas no Município de Morretes PR (2525'51,3” S, 4852'37,7” W), em novembro de 2007. O clima da região é classificado segundo a classificação de Köepen como Cfa. O solo da região é classificado como Cambissolo flúvico $\mathrm{Tb}$ Distrófico típico (EMBRAPA, 2006). O solo, na profundidade 0 a $20 \mathrm{~cm}$, em análise química e física prévia possuía $\mathrm{pH} \mathrm{CaCl}=5,4 ; \mathrm{Al}^{+3}=0,0 \mathrm{cmol}_{\mathrm{c}} \mathrm{dm}^{-}$ 3; $\mathrm{H}^{+}+\mathrm{Al}^{+3}=2,3 \mathrm{cmol}_{\mathrm{c}} \mathrm{dm}^{-3} ; \mathrm{C}^{+2}=2,20 \mathrm{cmol}_{\mathrm{c}} \mathrm{dm}^{-3}$; $\mathrm{Mg}^{+2}=0,60 \mathrm{cmol}_{\mathrm{c}} \mathrm{dm}^{-3} ; \mathrm{K}^{+}=0,1 \mathrm{cmol}_{\mathrm{c}} \mathrm{dm}^{-3} ; \mathrm{P}=30$ $\mathrm{mg} \mathrm{dm}{ }^{-3}$; saturação por bases $=52 \%$ e teor de argila $=250 \mathrm{~g} \mathrm{~kg}^{-1}$.

As mudas foram plantadas em espaçamento 1,0 x 1,0 m, com uma densidade de 10.000 plantas ha-1 (BIASI; DESCHAMPS, 2009). Em junho de 2009, nove meses após o corte da primeira rebrota, folhas e ramos finos foram coletados de 12 plantas e, as amostras foram homogeneizadas.

A secagem natural foi realizada dispondo as folhas em camadas finas à temperatura ambiente. Durante o período de secagem as folhas foram reviradas três vezes por dia, segundo recomendações de Rocha Neto et al. (2001), para evitar fermentação. Para a secagem artificial, as amostras de folhas foram secas em secador (FANEM - Mod. 320 SE) com circulação de ar forçada.

A extração do óleo essencial foi realizada por hidrodestilação em aparelho graduado tipo Clevenger, com balão volumétrico com capacidade de $2 \mathrm{~L}$, durante $4 \mathrm{~h}$. As extrações foram realizadas a partir de amostras de $50 \mathrm{~g}$, em triplicata, dos seguintes tratamentos: folhas frescas (extração realizada no mesmo dia da coleta do material); folhas secas à temperatura ambiente durante 6 dias; folhas secas à $40{ }^{\circ} \mathrm{C}$ durante 6 dias; folhas secas à temperatura ambiente durante 12 dias; folhas secas à $40^{\circ} \mathrm{C}$ durante 12 dias.

A análise dos constituintes do óleo essencial foi realizada por cromatografia em fase gasosa, em equipamento Agilent $6890 \mathrm{~N}$, com detector de ionização por chama (DIC), operando a $280{ }^{\circ} \mathrm{C}$ e uma coluna HP5 (30 m x 0,32 mm x 0,25 $\mu \mathrm{m})$, utilizando-se hidrogênio como gás de arraste $(1,5$ $\left.\mathrm{mL} \min ^{-1}\right)$. Foi injetado $1,0 \mu \mathrm{L}$ de uma solução com $1 \%$ de amostra em diclorometano em injetor aquecido a $250{ }^{\circ} \mathrm{C}$ operando no modo com divisão de fluxo (1:20). A programação de temperatura do forno foi de $60{ }^{\circ} \mathrm{C}$ a $240{ }^{\circ} \mathrm{C}$, a uma taxa de aquecimento de $3{ }^{\circ} \mathrm{C} \mathrm{min}^{-1}$. Para a quantificação, foram utilizados os valores de área normalizada, expresso em porcentagem.

Os espectros de massas foram obtidos em cromatógrafo Agilent $6890 \mathrm{~N}$ acoplado ao detector seletivo de massas Agilent 5973N, equipado com coluna capilar HP5MS (30 m x 0,32 mm x 0,25 $\mu \mathrm{m})$ utilizando hélio como gás carreador $\left(1,0 \mathrm{~mL} \mathrm{~min}^{-1}\right)$, nas mesmas condições utilizadas anteriormente. $\mathrm{O}$ detector foi operado no modo impacto eletrônico, 
com energia de ionização de $70 \mathrm{eV}$. Os índices de retenção para o óleo essencial foram calculados após a injeção de uma série homóloga de $n$-alcanos, nas mesmas condições utilizadas para as amostras. A identificação dos constituintes do óleo foi realizada por comparação dos índices de retenção calculados com os valores da literatura (ADAMS, 2007) e pela comparação dos espectros de massas obtidos com aqueles da biblioteca Wiley 6th ed (275.000).

$\mathrm{O}$ delineamento experimental foi inteiramente casualizado, com três repetições e quatro plantas por parcela útil. As análises de variância foram realizadas utilizando-se o programa estatístico ASSISTAT versão 7.4 beta (SILVA; AZEVEDO, 2006). As variâncias dos tratamentos foram testadas quanto à homogeneidade pelo teste de Bartlett e as médias dos tratamentos comparadas pelo teste de Scott-Knott a 5\% de probabilidade.

Foram identificados de oito a 15 componentes no óleo essencial de $P$. hispidinervum, dependendo do método de secagem utilizado, que corresponderam a $100 \%$ do total do óleo analisado (Tabela 1). O método e o tempo de secagem da biomassa alterou a composição do óleo essencial de pimenta longa. No óleo essencial extraído das folhas frescas foram identificados os constituintes mirceno e limoneno + $\beta$-felandreno, os quais não foram observados no óleo extraído das folhas secas dos demais tratamentos. O constituinte allo-aromadendreno esteve presente apenas no óleo extraído das folhas secas em estufas a $40{ }^{\circ} \mathrm{C}$ por 6 dias (Tabela 1 ).

O safrol, que representa o constituinte mais importante do óleo de pimenta longa, foi o composto majoritário encontrado nos óleos essenciais extraídos. Sendo as maiores porcentagens desse constituinte observadas no óleo extraído das folhas secas por um período de 12 dias, tanto para a secagem a temperatura ambiente $(90,1 \%)$, quanto em estufa a $40{ }^{\circ} \mathrm{C}(92,6 \%)$. Utilizando-se os mesmos métodos de secagem por um período menor (6 dias) os teores de safrol foram menores, obtendose $85,6 \%$ para secagem a temperatura ambiente e, $79,5 \%$ para secagem em estufa a $40{ }^{\circ} \mathrm{C}$, não atingindo o mínimo exigido para a comercialização. Em outro estudo com pimenta longa, Figueiredo et al. (2004), observaram que o prolongamento do tempo de secagem da biomassa reduziu o teor de safrol após o quarto dia de secagem, discordando com os resultados encontrados no presente estudo. No óleo extraído das folhas frescas apenas 78,2\% de safrol foi encontrado (Tabela 1).

As diferenças na porcentagem de safrol, observadas entre os métodos de secagem estudados neste trabalho, se devem ao fato de que, durante a secagem a fração química mais volátil do óleo essencial é eliminada pelo arraste do vapor d'água, elevando a concentração do safrol (PIMENTEL; MIRANDA, 2001). Por isso, quando o material vegetal foi seco a temperatura ambiente e a $40{ }^{\circ} \mathrm{C}$, durante 12 dias, a porcentagem de safrol foi elevada para $90,1 \%$ e $92,6 \%$, respectivamente (Tabela 1 ).

De acordo com os resultados obtidos concluise que o tipo e tempo de secagem alteram a constituição química do óleo essencial de pimenta longa. A secagem em estufa a $40{ }^{\circ} \mathrm{C}$ durante 12 dias reduz os constituintes do óleo essencial, porém com aumento do teor de safrol. 
Tabela 1. Valores médios dos teores dos compostos do óleo essencial de pimenta longa ( $P$. hispidinervum), em função do método de secagem. Curitiba, 2008.

\begin{tabular}{|c|c|c|c|c|c|c|c|}
\hline \multirow{2}{*}{$\mathrm{N}^{\mathrm{o}}$} & \multirow{2}{*}{ Componentes do óleo } & \multirow[b]{2}{*}{ IR } & \multicolumn{5}{|c|}{ Tratamentos de secagem } \\
\hline & & & 1 & 2 & 3 & 4 & 5 \\
\hline 1 & $\alpha$-Pineno & 937 & $0,1 \pm 0,2$ & $0,2 \pm 0,2$ & $0,1 \pm 0,2$ & - & $0,2 \pm 0,2$ \\
\hline 2 & Mirceno & 992 & $0,2 \pm 0,3$ & - & - & - & - \\
\hline 3 & Delta-3-Careno & 1012 & $0,6 \pm 0,3$ & $0,4 \pm 0,4$ & $0,4 \pm 0,4$ & $0,2 \pm 0,2$ & - \\
\hline 4 & Limoneno $+\beta$-Felandreno & 1032 & $0,2 \pm 0,4$ & - & - & - & - \\
\hline 5 & $(Z)-\beta$-Ocimeno & 1040 & $1,3 \pm 0,3$ & $0,5 \pm 0,5$ & $0,9 \pm 0,4$ & - & - \\
\hline 6 & $(E)-\beta$-Ocimeno & 1051 & $3,3 \pm 0,7$ & $1,4 \pm 0,8$ & $2,1 \pm 0,8$ & $0,3 \pm 0,3$ & - \\
\hline 7 & Terpinoleno & 1090 & $7,1 \pm 1,4$ & $3,5 \pm 1,7$ & $5,4 \pm 1,7$ & $0,8 \pm 0,1$ & - \\
\hline 8 & p-Cimen-8-ol & 1187 & - & $0,3 \pm 0,5$ & - & $1,0 \pm 0,1$ & $1,1 \pm 0,3$ \\
\hline 9 & Safrol & 1291 & $78,2 \pm 7$ & $85,6 \pm 10$ & $79,5 \pm 12$ & $90,1 \pm 2$ & $92,6 \pm 4$ \\
\hline 10 & $(E)$-Cariofileno & 1417 & $1,0 \pm 0,6$ & $0,9 \pm 0,8$ & $1,1 \pm 1,0$ & $0,9 \pm 0,4$ & $0,6 \pm 0,5$ \\
\hline 11 & Allo-Aromadendreno & 1459 & - & - & $0,2 \pm 0,4$ & - & - \\
\hline 12 & $\alpha$-Muuroleno & 1479 & $1,1 \pm 0,7$ & $0,7 \pm 0,6$ & $1,1 \pm 1,0$ & $0,2 \pm 0,3$ & $0,2 \pm 0,3$ \\
\hline 13 & Biciclogermacreno & 1494 & $5,2 \pm 3,2$ & $3,6 \pm 2,5$ & $6,7 \pm 4,5$ & $2,6 \pm 1,0$ & $1,8 \pm 1,2$ \\
\hline 14 & $n$-Pentadecano & 1499 & - & $1,2 \pm 1,0$ & $1,3 \pm 1,1$ & $1,2 \pm 0,1$ & $1,1 \pm 0,9$ \\
\hline 15 & $\begin{array}{l}\text { Germacreno D-4ol } \\
+ \text { Espatulenol }\end{array}$ & 1575 & $1,7 \pm 1,0$ & $1,7 \pm 1,6$ & $1,3 \pm 1,2$ & $2,4 \pm 0,1$ & $2,4 \pm 1,0$ \\
\hline & Total identificad & & 100 & 100 & 100 & 100 & 100 \\
\hline
\end{tabular}

1- Folhas frescas. 2- Secagem natural por 6 dias. 3- Secagem em estufa a $40^{\circ} \mathrm{C}$ por 6 dias. 4- Secagem natural por 12 dias. 5Secagem em estufa a $40^{\circ} \mathrm{C}$ por 12 dias. Dados representam médias \pm desvio padrão. IR $=$ Índice de Retenção. Médias \pm desvio padrão.

Fonte: Elaboração dos autores.

\section{Referências}

ADAMS, R. P. Identification of essential oils components by gás chromatography/mass spectroscopy. New York: Allured Publishing, 2007. 804 p.

BIASI, L. A.; DESCHAMPS, C. Plantas aromáticas do cultivo à produção de óleo essencial. Curitiba: Layer Studio, 2009. $160 \mathrm{p}$.

CAVAlCANTE, M. de J. B. Cultivo de pimenta longa (Piper hispidinervum) na Amazônia Ocidental. Rio Branco: Embrapa Acre, 2002. 29 p. (Sistemas de produção, 1).

EMPRESA BRASILEIRA DE PESQUISA AGROPECUÁRIA - EMBRAPA. Pimenta longa. Centro de informações de pimenta longa. 2009. Disponível em: $<$ http://www.embrapa.br/pimentalonga/ $>$. Acesso em: 29 jun. 2009.

. Sistema brasileiro de classificação de solos. Rio de Janeiro: Embrapa Solos, 2006.

FARIAS, M. R. Avaliação da qualidade de matériasprimas vegetais. In: SIMÕES, C. M. O. (Org.). Farmacognosia: da planta ao medicamento. Porto Alegre: Editora da UFRGS, 2007. p. 263-288.
FIGUEIREDO, F. J. C.; SANTOS, A. S.; ROCHA NETO, O. G.; ALVES, S. M. Secagem da biomassa aérea de pimenta longa sob condições de laboratório e de campo. 2004. Belém: Embrapa Amazônica Oriental, 45 p. (Boletim de Pesquisa e Desenvolvimento, 32).

LIMA, R. K.; CARDOSO, M. G.; MORAES, J. C.; MELO, B. A.; RODRIGUES, V. G.; GUIMARÃES, P. L. Atividade inseticida do óleo essencial de pimenta longa (Piper hispidinervum C. DC.) sobre lagarta-do-cartucho do milho Spodoptera frugiperda (J.E. Smith, 1797) (Lepidoptera: Noctuidae). Acta Amazonica, Manaus, v. 39, n. 2, p. 377-382, 2009.

MAIA, J. G. S.; SILVA, M. L.; LUZ, A. I. R.; ZOGHBI, M. G. B.; RAMOS, L. S. Espécies de Piper da Amazônia ricas em safrol. Química Nova, São Paulo, v. 10, n. 3, p. 200-204, 1987.

NASCIMENTO, F. R.; CARDOSO, M. G.; SOUZA, P. E.; LIMA, R. K.; SALGADO, A. P. S. P.; GUIMARÃES, L. G. L. Efeito do óleo essencial de pimenta longa (Piper hispidinervum C. DC) e do emulsificante Tween ${ }^{\circledR} 80$ sobre o crescimento micelial de Alternaria alternata (Fungi: Hyphomycetes). Acta Amazonica, Manaus, v. 38, n. 3, p. 503-508, 2008. 
PIMENTEL, F. A. Pimenta longa: de erva daninha a planta de interesse comercial. Rio Branco: EMBRAPA ACRE, 2000.

PIMENTEL, F. A.; MIRANDA, E. M. de. Eficiência de secadores solares com diferentes tipos de cobertura na secagem da biomassa de pimenta longa. In: PIMENTEL, F. A.; ROCHA NETO, O. da. Workshop de encerramento do projeto de desenvolvimento de tecnologias para produção de safrol a partir de pimenta longa (Piper hispidinervum). Rio Branco: Embrapa Acre, 2001. p. 153-158. (Documentos, 75).

RIVA, D.; SIMIONATTO, E. L.; WISNIEWSKI JUNIOR, A.; SALERNO, A. R.; SCHALLENBERGER, T. H. Estudo da adaptação da espécie Piper hispidinervum C.DC. (pimenta longa) à região do Vale do Itajaí - SC, através da composição química do óleo essencial obtido por hidrodestilação por micro-ondas e convencional. Acta Amazonica, Manaus, v. 41, n. 2, p. 297-302, 2011.

ROCHA NETO, O. G. da; FIGUEIRÊDO, F. J. C.; BACKER, D.; SANTOS, A. S. Beneficiamento de pimenta longa (Piper hispidinervium C.DC.). Belém: Embrapa Amazônia Oriental, 2001. 19 p. (Documentos, 98).

ROCHA, S. F. R.; MING, L. C. Piper hispidinervum: a sustainable source of safrole. In: JANICK, J. (Ed.). Perspectives on new crops and new uses. Alexandria: ASHS Press. 1999. p. 470-481.
ROSA, F. A. F.; NASCIMENTO, M. G.; REBELO, R. A.; PESCADOR, R. Avaliação da atividade regulatória de crescimento de compostos análogos ao ácido indol acético em sementes de alface. In: REUNIÃO ANUAL DA SOCIEDADE BRASILEIRA DE QUÍMICA, 23., 2000, Poços de Caldas. Livro de Resumos... Poços de Caldas: SBQ, v. 2, 2000. QB-10.

SILVA, F. A. S.; AZEVEDO, C. A. V. A new version of the assistat-statistical assistance software. In: WORD CONGRESS ON COMPUTERS IN AGRICULTURE, 4., 2006, Orlando, FL, USA. Anais... Orlando: American Society of Agricultural Engineers, 2006. p. 393-396.

SIMÕES, C. M. O.; SPITZER, V. Óleos voláteis. In: SIMÕES, C. M. O. (Org.). Farmacognosia: da planta ao medicamento. Porto Alegre: Editora da UFRGS, 2007. p. 467-495.

VAN DEN BERG, M.E. Plantas medicinais da Amazônia, contribuição ao seu conhecimento sistemático. Brasília, DF: PTU, 1983. 123 p.

ZACARONI, L. M.; CARDOSO, M. G.; SOUZA, P. E.; PIMENTEL, F. A.; GUIMARÃES, L. G. L.; SALGADO, A. P. S. P. Potencial fungitóxico do óleo essencial de Piper hispidinervum (pimenta longa) sobre os fungos fitopatogênicos Bipolaris sorokiniana, Fusarium oxysporum e Colletotrichum gloeosporioides. Acta Amazonica, Manaus, v. 39, n. 1, p. 193-198, 2009. 